\title{
The sphenozygomatic fissure
}

\author{
M.C. Rusu1'10, F. Pop², M. Săndulescu³ \\ 'Division of Anatomy, Faculty of Dental Medicine, "Carol Davila" University of Medicine and Pharmacy, Bucharest, Romania \\ 2Division of Pathologic Anatomy, Faculty of Medicine, "Carol Davila" University of Medicine and Pharmacy, Bucharest, \\ Romania \\ ${ }^{3}$ Division of Implant Prosthetic Rehabilitation, Faculty of Dental Medicine, "Carol Davila" University of Medicine and \\ Pharmacy, Bucharest, Romania
}

[Received: 3 January 2020; Accepted: 3 February 2020]

\begin{abstract}
The lateral (temporal) wall of the orbit separates it from the temporal fossa and the anterior part of the temporal muscle. Within this wall, the sphenozygomatic suture joins the greater wing of the sphenoid bone and the zygomatic bone. We retrospectively documented in cone-beam computed tomography the anatomy of the orbit in a 56-year-old female and we found a previously unreported anatomic variant. The greater wing of the sphenoid bone and the zygomatic bone were separated, bilaterally, by a large unossified space which we termed the sphenozygomatic fissure. This was merged inferiorly with the inferior orbital fissure. A possible imbalanced mechanism of membranous ossification of both the zygomatic bone and the orbital surface of the greater wing could be speculated as a possible cause for such sphenozygomatic fissure. This previously undocumented anatomic variant is of high clinical relevance, since it may allow orbital fat to herniate (or bulge) toward the temporal fossa, it may be easily damaged during minor trauma and it should be carefully approached during the surgery of the orbit through the lateral wall. (Folia Morphol. 2021; 80, 1: 219-221)
\end{abstract}

Key words: orbit, cone-beam computed tomography, temporal fossa, orbital hernia, hiatus

\section{INTRODUCTION}

The orbit is a 4-sided pyramid with walls that are built-up by either viscerocranial, or neurocranial bones [7]. The sphenozygomatic suture connects the greater wing of the sphenoid bone and the zygomatic bone on the lateral wall of the orbit [7].

The development of the orbit at the junction between the cranial membranous bones and the basal endochondral bones is complex [3]. Orbital bones initially form as a network of tiny bony ossification zones centrally, separated by large non-ossified areas [10]. As ossification proceeds, separate ossification zones gradually approach each other leaving unossified spaces in between [10].
Various cranial abnormalities are caused by a cessation of the development of specific structures at specific times. For example, defects in the apposition of the junctions of embryological fissures lead to clefting syndromes [3].

The inferior orbital fissure (IOF) was described by Lang (2011) [6]: it is wider laterally and narrower medially, being bordered superiorly by the greater sphenoidal wing and inferiorly by the maxillary bone. According to Lang's description, further quoted in Bergman's Comprehensive Encyclopedia of Human Anatomic Variation [2], the anterolateral segment of the IOF may be formed by either the zygomatic bone (50\%) or the sphenoid and maxillary bones $(50 \%)$. In rare

Address for correspondence: M.C. Rusu, MD, PhD (Med.), PhD (Biol.), Dr. hab., Prof., "Carol Davila" University of Medicine and Pharmacy, 8 Eroilor Sanitari Blvd., RO-050474, Bucharest, Romania, tel: +40722363705, e-mail: anatomon@gmail.com 


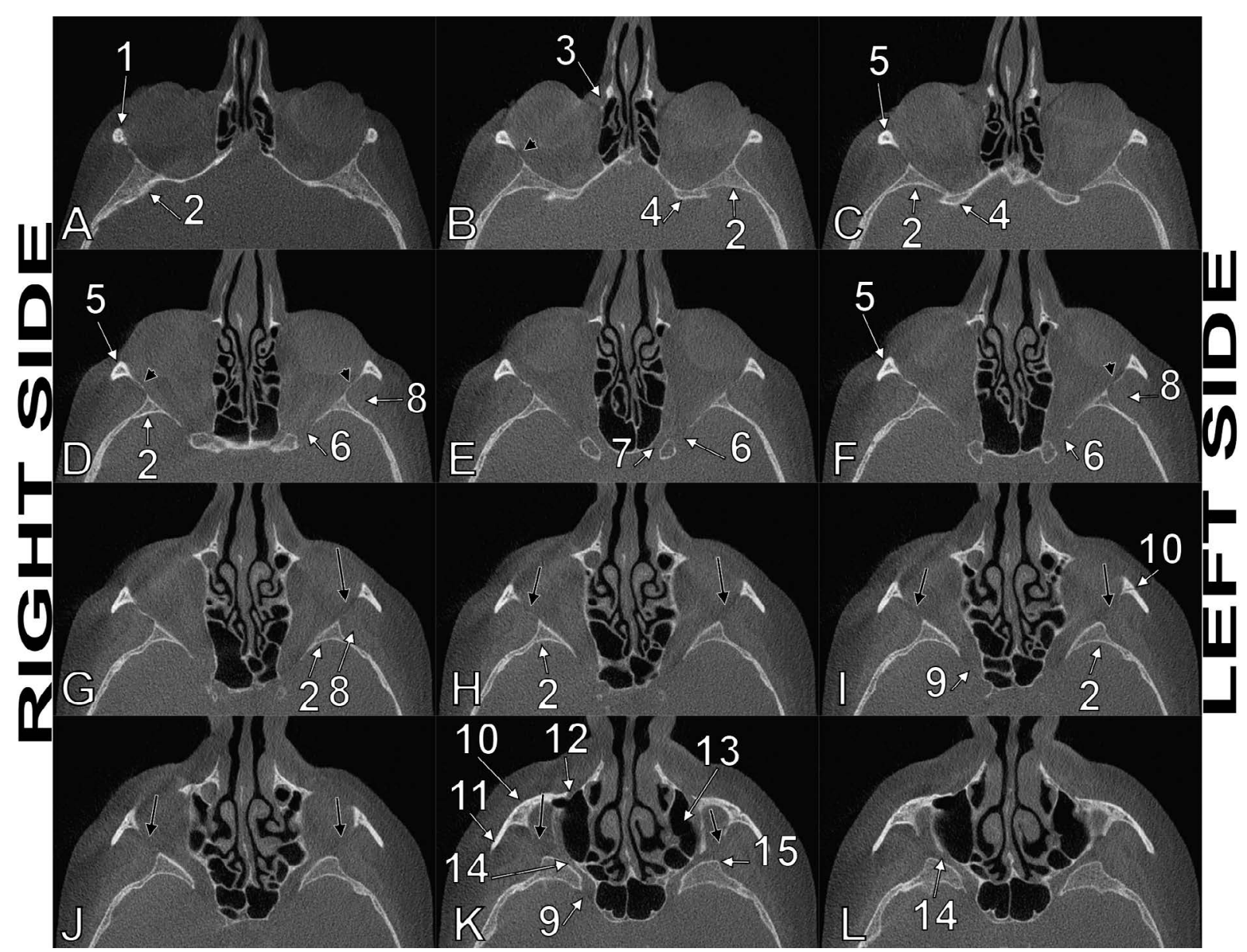

Figure 1. Axial slices through the orbits, superior-to-inferior series (A-L); 1 - zygomatic process of the frontal bone; 2 - greater wing of the sphenoid bone; 3 - lacrimal fossa; 4 - lesser wing of the sphenoid bone; 5 - frontal process of the zygomatic bone; 6 - superior orbital fissure; 7 - optic canal; 8 - deep anterior portion of the temporal muscle; 9 - foramen rotundum; 10 - zygomatic bone; 11 - temporal process of the zygomatic bone; 12 - infraorbital foramen; 13 - maxillary sinus; 14 - inferior orbital fissure; 15 - infratemporal spine (sphenoidal tubercle). The lateral walls of each orbit are superiorly thinned (black arrowheads) and inferiorly dehiscent (black arrows) at the sphenozygomatic junction (sphenozygomatic fissure).

cases, especially in older persons, the antero-lateral segment of the IOF may be thinned, which allows the orbital fat to herniate toward the temporal fossa [6]. Anatomical restrictions for such "fat hernia" relate to the deepest portion of the temporal muscle that originates, occasionally, from the periorbital region and the pericranium covering the orbital muscles thus forming the closing plate of the IOF [6]. This single previous report on the possibilities of variation of the IOF does not cover, however, the possibility of a superior extension of the IOF, as a sphenozygomatic fissure, or hiatus, within the lateral orbit wall.

\section{CASE REPORT}

A retrospective cone-beam computed tomography (CBCT) study of the archived files of a 56 -year-old female patient was performed.
The subject had been scanned using a CBCT machine - iCat (Imaging Sciences International), the DICOM file being further documented with the Planmeca Romexis Viewer 3.5.0.R software, according to a previously detailed study protocol [9]. We evaluated the orbit walls in all the three anatomical planes, as well as the three-dimensional volume renderisations. The orbit floor was fitted in the horizontal plane. Relevant anatomical features were exported as image files. The patient has given written informed consent for all medical data to be used for research, provided they are anonymised.

The patient had the temporal walls of both orbits largely incomplete on the entire height, this being accurately documented on serial axial slices (Fig. 1). The lack of bone was identified at the junction of the greater sphenoidal wing with the zygomatic bone, 
thus in the anatomical situs of the sphenozygomatic suture. We termed sphenozygomatic fissure the dehiscence of the lateral orbital wall. We also observed it was continuous with the IOF, thus extending the IOF upwards, between the orbit and the temporal fossa. The anterior part of the temporal muscle was located immediately posterior to that sphenozygomatic fissure and was inserted onto the pericranium obturating the fissure. We did not find any evidence of tissue hernias from the orbit into the temporal fossa.

\section{DISCUSSION AND CONCLUSIONS}

Different imaging techniques are currently used to study the skull bones; however, $\mathrm{CBCT}$ images are superior over others for the bony anatomy and muscle attachments $[5,8]$. Therefore, the CBCT method is reliable enough to assess this possible, but previously unreported, anatomic variant of the temporal wall of the orbit - the sphenozygomatic fissure.

This bilateral anatomical "defect", or cleft, of the orbit can predispose the patient to fractures of the orbital wall, even after a moderate trauma, or change the fracture pattern, as it changes the resistance structure of the cranium. Moreover, it is likely that orbital fat hernias could enter the temporal fossa not only through the IOF, but also via such a sphenozygomatic fissure, which is a wider passage. Therefore, if the anterior section of the temporal fossa is approached, extreme traction of orbital fat hernias should be avoided [6]. These large sphenozygomatic defects of the temporal wall of the orbit recommend delicate manoeuvres during lateral orbital approaches when the surgeon uses a pure zygomatic osteotomy [11]. Also, as the zygomatic bone is commonly involved in facial trauma, zygomatic fractures with displacement could lead to blow-in orbital fractures, especially when the temporal fossa anterior wall is thinned or incomplete, as in this case.

The bones of the chondrocranium usually have endochondral ossification centres, while the facial bones are formed by membranous ossification [12]; this however does not apply to the greater wing of the sphenoid bone (alisphenoid), which has both intramembranous and endochondral components [4]. The intramembranous part of the alisphenoid replaces the orbital cartilage [4], thus participating in the lateral wall of the orbit. While the ossification of the zygomatic bone starts in weeks 23-31, that of the greater wing of the sphenoid bone begins later, in weeks 55-68 [10]. Therefore, an incomplete membranous ossification of the temporal wall of the may explain the formation of these bilateral sphenozygomatic fissures. This mechanism could mirror the congenital anomalies of the sphenoid bone that are likely to occur at the fusion planes of the ossified cartilaginous precursors during development [1].

\section{REFERENCES}

1. Bendersky DC, Landriel FA, Ajler PM, et al. Sternberg's canal as a cause of encephalocele within the lateral recess of the sphenoid sinus: a report of two cases. Surg Neurol Int. 2011; 2: 171, doi: 10.4103/2152-7806.90034, indexed in Pubmed: 22145089.

2. Bergman RA, Tubbs RS, Shoja MM, Loukas M. Bergman's comprehensive encyclopedia of human anatomic variation. John Wiley \& Sons, Hoboken, New Jersey 2016.

3. Dollfus $H$, Verloes A. Dysmorphology and the orbital region: a practical clinical approach. Survey Ophthalmology. 2004; 49(6): 547-561, doi: 10.1016/s00396257(04)00133-x.

4. Gray H, Standring S, Anand N, Birch R, Collins P, Crossman A, Gleeson $M$, Jawaheer G, Smith AL, Spratt JD, Stringer MD, Tubbs SR, Tunstall R, Wein AJ, Wigley CB. Gray's anatomy: The anatomical basis of clinical practice. 41 ed. Elsevier, London, UK 2016.

5. Hegde S, Praveen B, Shetty S. Morphological and radiological variations of mandibular condyles in health and diseases: a systematic review. Dentistry. 2013; 3(1), doi: 10.4172/2161-1122.1000154.

6. Lang J. Skull base and related structures: Atlas of clinical anatomy. Schattauer, Verlag 2001.

7. Maliborski A, Różycki R. Diagnostic imaging of the nasolacrimal drainage system. Part I. Radiological anatomy of lacrimal pathways. Physiology of tear secretion and tear outflow. Med Sci Monit. 2014; 20: 628-638, doi: 10.12659/MSM.890098, indexed in Pubmed: 24743297.

8. Rusu MC, Dincă D. Accessory pterygoid fovea of the human mandibular condyle. Cranio. 2019 [Epub ahead of print]: 1-5, doi: 10.1080/08869634.2019.1635674, indexed in Pubmed: 31241001.

9. Rusu MC, Sava CJ, Ilie AC, et al. Agger nasi cells versus lacrimal cells and uncinate bullae in cone-beam computed tomography. Ear Nose Throat J. 2019; 98(6): 334-339, doi: 10.1177/0145561319840836, indexed in Pubmed: 31012345.

10. Tawfik HA, Dutton JJ. Embryologic and fetal development of the human orbit. Ophthalmic Plast Reconstr Surg. 2018; 34(5): 405-421, doi: 10.1097/IOP.0000000000001172, indexed in Pubmed: 30134385.

11. Villalonga JF, Sáenz A, Revuelta Barbero JM, et al. Surgical anatomy of the orbit. A systematic and clear study of a complex structure. Neurocirugia (Astur). 2019; 30(6): 259-267, doi: 10.1016/j.neucir.2019.04.003, indexed in Pubmed: 31221573.

12. Zhang Q, Wang H, Udagawa J, et al. Morphological and morphometric study on sphenoid and basioccipital ossification in normal human fetuses. Congenit Anom (Kyoto). 2011; 51(3): 138-148, doi: 10.1111/j.17414520.2011.00322.x, indexed in Pubmed: 21848997. 